\title{
Subarachnoid Dissemination of Pineal Germinoma 9 Years After Radiation Therapy without Local Relapse - Case Report-
}

\author{
Kazuhiko TOKoro, Yasuhiro CHIBA, Shizuo MURASE*, \\ Saburo YAGISHITA** and Yoshikazu KYUMA*** \\ Departments of Neurosurgery, ${ }^{*}$ Orthopedic Surgery, and \\ **Pathology, Kanagawa Rehabilitation Center, Atsugi, Kanagawa; \\ ***Department of Neurosurgery, Kanagawa Cancer Center, Yokohama
}

\begin{abstract}
A 22-year-old female developed intracranial and spinal subarachnoid metastases 9 years after radiation therapy for a pineal germinoma. Computed tomographic scans showed no evidence of local recurrence. Cerebrospinal axis irradiation achieved total remission. Delayed subarachnoid dissemination may be caused by germinoma cells remaining dormant in the subarachnoid space, outside the radiation field.
\end{abstract}

Key words: germinoma, subarachnoid dissemination, spinal metastasis, pineal region, radiation therapy

\section{Introduction}

Germinomas are highly radiosensitive and are one of the few intracranial tumors controllable by radiation therapy alone. $\left.{ }^{1,2,8,10} \cdot 12,18,21,23,25-28\right)$ An inadequate radiation field (local, $<30 \mathrm{~cm}^{2}$ ) or dose $(<45 \mathrm{~Gy})$ may cause local relapse. ${ }^{1,2.5,10.18,23.28)}$ The optimum dose is $40 \mathrm{~Gy}$ to the entire ventricular system, followed by a tumor bed dose of $50-55 \mathrm{~Gy} .{ }^{12,18}$ However, subarachnoid dissemination cannot be completely prevented. ${ }^{1,2,5,8,10-12,18,23-28)}$ Prophylactic spinal irradiation is recommended in selected cases because of the efficacy, in spite of the complications, particularly in children. $2.5,8,10,17-19,23)$

The risk of meningeal seeding in pineal germinoma is approximately $4-25 \%, 1,2,5.8,10,11,18,21,23,25-27)$ Subclinical metastases detected by computed tomography (CT) occur in more than $60 \%$ of cases, ${ }^{3,8)}$ as with medulloblastoma. ${ }^{71}$

Subarachnoid dissemination may develop without local relapse. Sung et al. ${ }^{23)}$ reported that of $11 \mathrm{pa}$ tients with spinal metastases, eight had no local recurrence, two had intracranial metastases, and one manifested spinal metastases during cranial irradia-

Received June 25, 1990; Accepted March 4, 1991 tion. Subarachnoid dissemination usually occurs within 6 months $^{2)}$ or a few years ${ }^{2.3)}$ of initial diagnosis. A tumor appearing regressive on CT scan after radiation therapy may remain active and seed in the subarachnoid space. ${ }^{1,28)}$ Delayed subarachnoid dissemination in intracranial germinoma is rare. ${ }^{5,6,14,23)}$

We present a patient who developed subarachnoid dissemination without local relapse 9 years after initial radiation therapy for a pineal germinoma. The mechanism of delayed presentation is discussed.

\section{Case Report}

This patient developed morning headache and vomiting when aged 11 years, and was referred to our hospital in October, 1977. She was alert and oriented with anisocoria (lt $>\mathrm{rt}$ ), bilaterally sluggish light reflexes, choked dises, left hemihypesthesia including the face, and polyuria $(3000 \mathrm{ml} /$ day $)$. The alpha-fetoprotein (AFP), human chorionic gonadotropin (HCG), and cerebrospinal fluid (CSF) cytology were not examined. CT scans showed a homogeneously enhanced round mass in the pineal region and hydrocephalus (Fig. 1 upper).

A ventriculoperitoneal (VP) shunt was emplaced. Local irradiation $5020 \mathrm{cGy}\left({ }^{60} \mathrm{Co}\right)$ by moving beam 


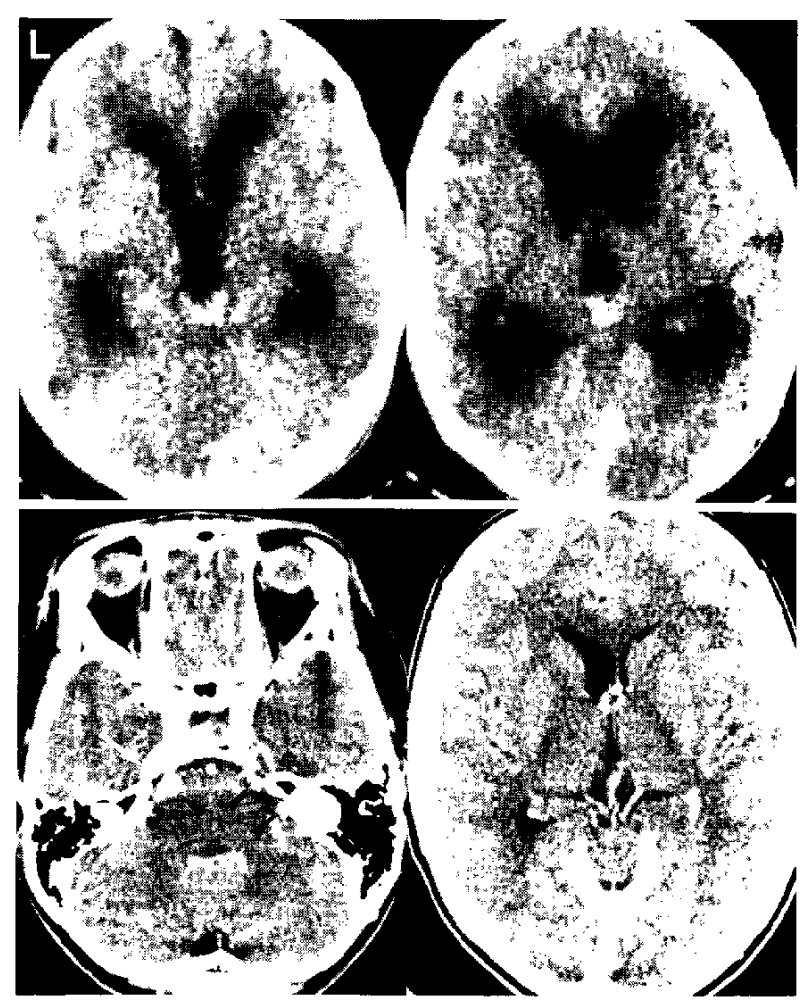

Fig. 1 upper: Initial CT scans, showing a homogeneously enhanced round mass in the pineal region and ventriculomegaly. lower: CT scans 9 years after initial radiation therapy, showing enhanced mass lesions in the bilateral cerebellopontine angles (arrowheads), prepontine cistern, and Meckel's caves (arrow). Other areas including both pineal and suprasellar regions are normal.

$5 \times 5 \mathrm{~cm}, 25 \mathrm{~cm}^{2}$, was given in 46 fractions over 14 weeks. No whole brain or spinal irradiation was performed. Although the shunt controlled the hydrocephalus, diabetes insipidus (urine output, $3000-5000 \mathrm{ml} /$ day) developed during radiation therapy. The tumor was no longer visualized by CT after radiation therapy, which strongly suggested pineal germinoma. She returned to school and did well until readmission. Follow-up was interrupted after 1979.

She developed gait disturbance and pain at the right thigh and hip from a fall when aged 22 years in February, 1987. The progressive symptoms were accompanied by disturbance of mouth opening, facial spasm, hearing disturbance, tinnitus, and impaired urinary and bowel control. Polyuria and polydipsia had persisted since 1978. She was readmitted in October, 1987.

Neurological examination revealed hypesthesia in the left side of the face and bilateral legs, left hearing disturbance, paraparesis, and bilateral straight leg raising limited to $45^{\circ}$. No pupillary abnormalities or Parinaud's sign was noted. Serum AFP, HCG, and carcinoembryonic antigen levels were within normal ranges. The CSF cytology was not unusual. CT scans showed enhanced mass lesions in the bilateral cerebellopontine angles, prepontine cistern, and Meckel's caves (Fig. 1 lower). Other areas including both pineal and suprasellar regions were normal. Myelograms demonstrated multiple nodules along the cauda equina with a block at S1 (Fig. 2). Intracranial and spinal subarachnoid dissemination of germinoma without local relapse was diagnosed.

The peritoneal catheter was ligated to prevent systemic dissemination via the VP shunt. ${ }^{13,16)}$ However, she developed acute hydrocephalus requiring shunt revision. An L4 to S1 laminectomy and multiple subarachnoid nodule biopsy were performed in November, 1987. Histological examination demonstrated pure germinoma (Fig. 3 left ). Immunohistochemical analysis identified placental alkaline phosphatase (PLAP) ${ }^{22)}$ (Fig. 3 right). Whole brain (35 Gy in 19 fractions), cervicothoracic (24 Gy in 16 fractions), and lumbosacral ( $42 \mathrm{~Gy}$ in $28 \mathrm{frac}-$ tions) Lineac irradiation was given over 7 weeks. No tumor was visible on CT scans after re-irradiation. All symptoms except the left hearing disturbance sub-

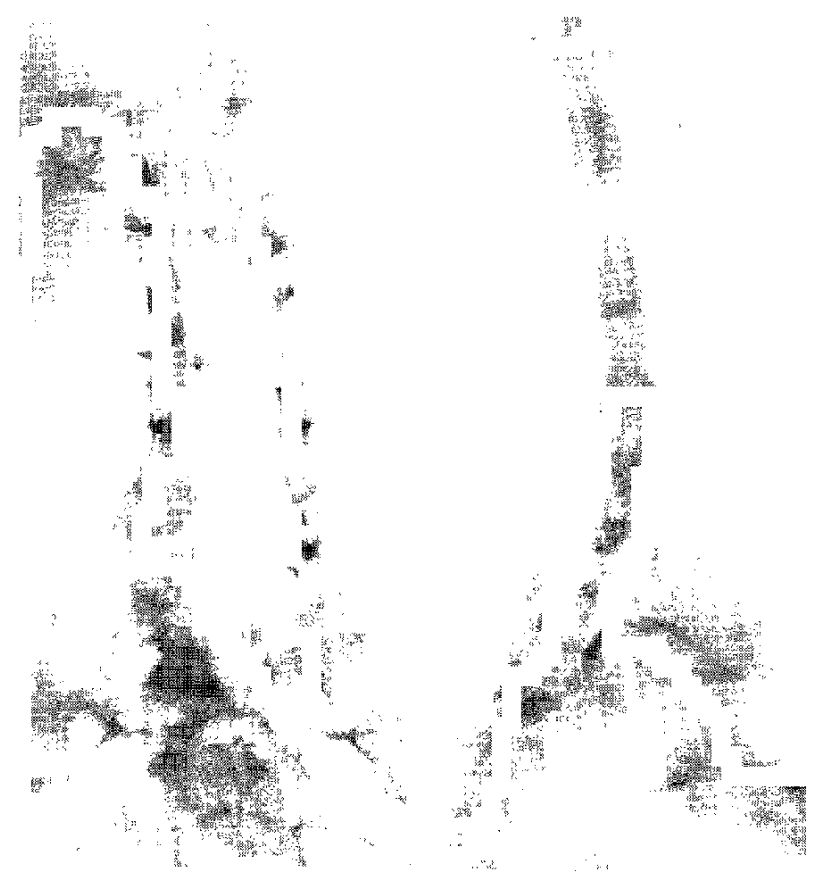

Fig. 2 Myelograms, showing multiple nodular defects along the cauda equina with a block at S1. 


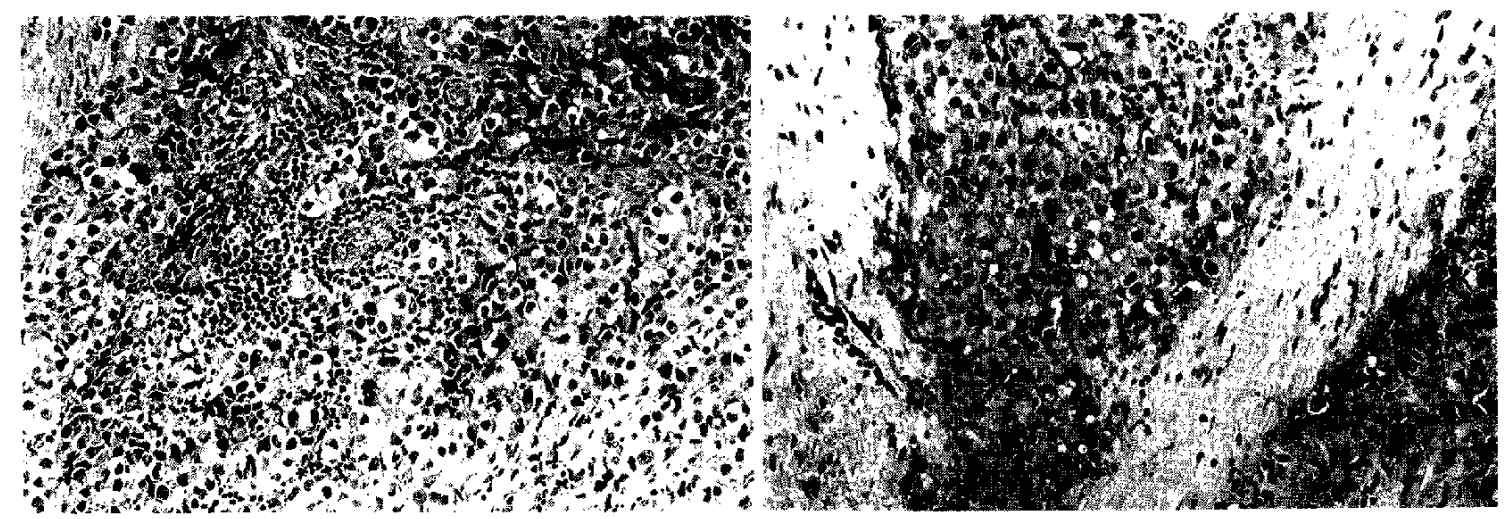

Fig. 3 Photomicrographs of the tumor. left: There are typical features of pure germinoma, including polygonal epithelial and lymphoid cells in the fibrous stroma. HE stain, $\times 200$. right: A positive reaction to $\mathrm{PL} A \mathrm{P}$ is seen. $\times 200$.

sided. Leukocytopenia prevented chemotherapy. There has been no evidence of recurrence for 2 years.

\section{Discussion}

Kunishio et $a l^{14)}$ reported a 28 -year-old male with mixed germ-cell tumor in the pineal region, who developed spinal metastasis 11 years after initial cranial radiation therapy. They considered that germinoma cells had already disseminated into the subarachnoid space before irradiation, although seeding from a recurrent pineal tumor (mainly teratoma) was also possible. Dayan et al. ${ }^{6)}$ reported a 21-year-old male with pinealoma who developed spinal metastasis without local relapse 7 years after deep x-ray therapy. Bradfield and Perez ${ }^{5 /}$ reported a 19-year-old male with pinealoma who developed spinal metastasis without local relapse 4 years after brain irradiation ( $\left.5850 \mathrm{cGy}, 121 \mathrm{~cm}^{2}\right)$. Sung et al. ${ }^{23)} \mathrm{ex}-$ perienced a suprasellar and a pineal germinoma which caused metastases 4 and 5 years after initial irradiation, respectively.

What then are the factors controlling subarachnoid dissemination of germinomas? Germinoma, like medulloblastoma, has no adhesive factor preventing tumor cell dissociation into the subarachnoid space. It does have stromal fibronectin which accelerates the attachment of migrating tumor cells to new sites. ${ }^{15)}$ Pineal teratoma or mixed germ-cell tumors only disseminate germinomatous components. ${ }^{14,24)}$

The labeling index of testicular seminomas is $11 \%,{ }^{20)}$ comparable to medulloblastomas $\left.(12 \%) .{ }^{9}\right)$ The labeling index of intracranial germinomas is presently unreported. However, germinoma cells demonstrate lower proliferation and malignancy than medulloblastoma. ${ }^{4)}$ Delayed subarachnoid dissemination and/or local recurrence may be caused by germinoma cells remaining dormant for many years in the subarachnoid space, outside the radiation field. ${ }^{5,6,14,23)}$ Our patient developed diabetes insipidus in an early stage, suggesting that germinoma cells had already disseminated into the intracranial and spinal subarachnoid spaces before initial radiation therapy, although not demonstrated conclusively by $\mathrm{CT}$.

Spinal axis irradiation after manifestation of spinal metastases may achieve long-term control. $45 \%$ of patients with spinal metastases survive more than 2 years following spinal cord radiation therapy. ${ }^{23)}$ Aida et al. ${ }^{2)}$ achieved control of spinal metastasis for 11 years after re-irradiation. However, some spinal metastases have recurred after spinal irradiation. ${ }^{1,5,6)}$ Craniospinal irradiation may develop complications, particularly in young people, ${ }^{17,19)}$ so cis-platinum multidrug combination therapy is now the treatment of choice for both primary and recurrent germinomas. ${ }^{3,13,16)}$

\section{Acknowledgments}

We thank Drs. Akitoshi Nakamori and Hiroyuki Abe of Kanagawa Rehabilitation Center, Dr. Akimune Hayashi of Kanagawa Cancer Center, Dr. Gabriel Symonds of Tokyo Medical and Surgical Clinic, and Dr. Julio S. Brossard Alejo of Hospital Infantil Sur Santiago de Cuba in Cuba, for their assistance in producing this paper.

\section{References}

1) Abay EO II, Laws ER Jr, Grado GL, Bruckman JE, 
Forbes GS, Gomez MR, Scott M: Pineal tumors in children and adolescents. Treatment by CSF shunting and radiotherapy. I Neurosurg 55: 889-895, 1981

2) Aida $T$, Abe H, Tsuru M: Treatment and prognosis of primary intracranial germ cell tumors. With special reference to local recurrence and spinal metastasis. Neurol Med Chir (Tokyo) 23: 447-455, 1983 (in Japanese)

3) Allen JC, Kim JH, Packer RJ: Neoadjuvant chemotherapy for newly diagnosed germ-cell tumors of the central nervous system. $J$ Neurosurg $67 ; 65-70$, 1987

4) Berry MP, Jenkin RDT, Keen CW, Nair BD, Simpson WJ: Radiation treatment for medulloblastoma. A 21-year review. J Neurosurg 55: 43-51, 1981

5) Bradfield JS, Perez CA: Pineal tumors and ectopic pinealomas. Analysis of treatment and failures. Radiology 103: 399-406, 1972

6) Dayan AD, Marshall AHE, Miller AA, Pick FJ, Rankin NE: Atypical teratomas of the pineal and hypothalamus. J Path Bact 92: 1-28, 1966

7) Deutsch M, Reigel DH: The value of myelography in the management of childhood medulloblastoma. Cancer 45: 2194-2197, 1980

8) Handa $\mathrm{H}$, Yamashita $\mathrm{J}$ : Current treatment of pineal tumors. Neurol Med Chir (Tokyo) 21: 147-154, 1981 (in Japanese)

9) Hoshino T, Kobayashi S, Townsend JJ, Wilson CB: A cell kinetic study on medulloblastomas. Cancer 55: 1711-1713, 1985

10) Jenkin RDT, Simpson WJK, Keen CW: Pineal and suprasellar germinomas. Results of radiation treatment. J Neurosurg 48: 99-107, 1978

11) Jennings MT, Gelman R, Hochberg F: Intracranial germ-cell tumors: Natural history and pathogenesis. J Neurosurg 63: 155-167, 1985

12) Jooma R, Kendall BE: Diagnosis and management of pineal tumors. $J$ Neurosurg 58: 654-665, 1983

13) Kobayashi $T$, Yoshida $J$, Ishiyama J, Noda S, Kito A, Kida $Y$ : Combination chemotherapy with cisplatin and etoposide for malignant intracranial germ-cell tumors. An experimental and clinical study. $J$ Neurosurg 70: 676-681, 1989

14) Kunishio K, Yamamoto $Y$, Suga M, Sunami N, Yamamoto Y, Ohtsuki Y: Spinal metastasis detected 11 years after initial treatment for pineal germ cell tumor. Case report. Neurol Med Chir (Tokyo) 28: 491-497, 1988 (in Japanese)

15) Kuratsu J, Ishimaru Y, Uemura S: Possible roles of adhesive factor, stromal fibronectin, and peanut agglutinin receptor in subarachnoid dissemination of brain tumor cells. Neurol Med Chir (Tokyo) 29: 8487, 1989 (in Japanese)

16) Neuwelt EA, Frenkel EP, Smith RG: Suprasellar germinomas (ectopic pinealomas): Aspects of immunological characterization and successful chemo- therapeutic responses in recurrent disease. Neurosurgery 7: 352-358, 1980

17) Onoyama $Y$, Abe M, Takahashi M, Yabumoto E, Sakamoto $\mathrm{T}$ : Radiation therapy of brain tumors in children. Radiology 115: 687-693, 1975

18) Onoyama $Y$, Ono K, Nakajima $T$, Hiraoka M, Abe M: Radiation therapy of pineal tumors. Radiology 130: 757-760, 1979

19) Packer RJ, Sutton LN, Atkins TE, Radcliffe J, Bunin GR, D'Angio G, Siegel KR, Schut L: A prospective study of cognitive function in children receiving whole-brain radiotherapy and chemotherapy: 2-year results. I Neurosurg 70: 707-713, 1989

20) Rabes HM: Proliferation of human testicular tumours. Int J Androl 10: 127-137, 1987

21) Sano K: Pineal region tumors: Problems in pathology and treatment. Clin Neurosurg 30: 59-91, 1982

22) Shinoda J, Miwa Y, Kondoh H, Andoh T, Sakai N, Yamada H, Ikeda T, Shimokawa K, Takahashi M: Immunohistochemical study of primary intracranial germinomas and testicular seminomas. Special reference to placental alkaline phosphatase. Shinkei Kenkyu No Shinpo 31: 127-140, 1987 (in Japanese)

23) Sung DI, Harisiadis L, Chang CH: Midline pineal tumors and suprasellar germinomas: Highly curable by irradiation. Radiology 128: 745-751, 1978

24) Tsuchida T, Tanaka R, Kobayashi K, Ueki K, Koizumi R, Oyake $Y$ : A case of two cell pattern pinealoma, developed 15 years after total removal of pineal teratoma. No To Shinkei 28: 893-899, 1976 (in Japanese)

25) Ueki K, Tanaka R: Treatments and prognoses of pineal tumors. Experience of 110 cases. Neurol Med Chir (Tokyo) 20: 1-26, 1980

26) Waga $S$, Handa $H$, Yamashita J: Intracranial germinomas: Treatment and results. Surg Neurol 11: $167-172,1979$

27) Wara WM, Jenkin RDT, Evans A, Ertel I, Hittle R, Ortega J, Wilson CB, Hammond D: Tumors of the pineal and suprasellar region: Childrens Cancer Study Group treatment results 1960-1975. A report from Childrens Cancer Study Group. Cancer 43: 698-701, 1979

28) Wood JH, Zimmerman RA, Bruce DA, Bilaniuk LT, Norris DG, Schut L: Assessment and management of pineal-region and related tumors. Surg Neurol 16: $192-210,1981$

Address reprint requests to: K. Tokoro, M.D., Department of Neurosurgery, Kanagawa Rehabilitation Center, 516 Nanasawa, Atsugi, Kanagawa 243-01, Japan. 